\title{
SARNA SARCÓPTICA EM CÃES: UMA BREVE REVISÃO
}

\section{Luiz Carlos de ALMEIDA ${ }^{\mathbf{1}}$; Gil Dutra FURTADO ${ }^{2}$ Leonardo Alves de FARIAS $^{\mathbf{3}}$}

\author{
${ }^{1}$ Graduando em Medicina Veterinária/Centro Universitário Maurício de Nassau, João Pessoa-PB \\ (UNINASSAU). E-mail: luizemidia1@ @otmail.com \\ ${ }^{2}$ Graduando em Medicina Veterinária/UNINASSAU; Engenheiro Agrônomo/Universidade Federal da Paraíba \\ (UFPB); Doutor em Psicobiologia/Universidade Federal do Rio Grande do Norte (UFRN); Sócio da Cooperativa \\ de Agronegócio (COOPAGRO). E-mail: gdfurtado@ hotmail.com \\ ${ }^{3}$ Mestre; Médico Veterinário; Professor/UNINASSAU. E-mail: leovetleleco@gmail.com
}

Resumo. A sarna sarcóptica é a infecção apresentada na pele, causada pelo ácaro Sarcoptes scabiei. Dentre os animais, o cão doméstico (Canis lupus familiaris), é o animal mais atingido, especialmente quando este é um cão sem tutor ou que se encontra em um Centro de Vigilância Ambiental e Zoonoses. Mediante a metodologia de revisão bibliográfica, desenvolveu-se esta pesquisa com o objetivo de esclarecer, para a comunidade em geral, informações sobre a sarna sarcóptica, onde se conclui que esta doença é de fácil propagação em ambientes onde não se tem um bom controle de higienização.

Palavras-chave: Zoonose; Propagação; Ectoparasitas.

\section{SARCOPTIC SCABIES IN DOGS: A BRIEF REVIEW}

Abstract. Sarcoptic scabies is the infection on the skin, caused by the mite Sarcoptes scabiei. Among the animals, the domestic dog (Canis lupus familiaris) is undoubtedly the most affected animal, especially when it is a dog without a guardian or in a Center for Environmental Surveillance and Zoonoses. Through the bibliographic review methodology, this research was developed with the purpose of clarifying for the community in general, information about Sarcóptica mange, where it is concluded that this disease is easily spread in environments where there is not a good hygiene control.

Keywords: Zoonosis; Propagation; Ectoparasites.

\section{SARNA SARCÓPTICA EN PERROS: UNA BREVE REVISIÓN}

Resumen. La sarna Sarcóptica es la infección presentada en la piel, causada por el ácaro Sarcoptes scabiei. Entre los animales, el perro doméstico (Canis lupus familiaris), es el animal más afectado, especialmente cuando éste es un perro sin tutor o que se encuentra en un Centro de Vigilancia Ambiental y Zoonosis. Mediante la metodología de revisión bibliográfica, se desarrolló esta investigación con el objetivo de esclarecer para la comunidad en general, informaciones sobre la sarna 
sarcóptica, donde se concluye que esta enfermedad es de fácil propagación en ambientes donde no se tiene un buen control de higienización.

Palabras clave: Zoonosis; Propagación; Ectoparásitos.

\section{INTRODUÇÃO}

A sarna sarcóptica é a infecção apresentada na pele, causada pelo ácaro Sarcoptes scabiei. Estes ácaros são microscópicos e não podem ser vistos a olho nu. Este parasita se aloja na pele dos animais e gera uma dermatite pruriginosa severa e generalizada. O local afetado do animal se apresenta com pequenas crostas hemorrágicas com perda da pelagem nas regiões ventral, axilar, codilhos e curvilhões, bem como no focinho. Na maioria dos casos, porém, o quadro clínico pode vir a ser bem mais abrangente (TAYLOR; COOP; WALL, 2017).

Esta dermatite é marcada pela produção exagerada de gordura, dando um aspecto e odor desagradável ao animal. O prurido intenso pode mascarar as lesões primárias com o aparecimento de feridas provocadas pelo coçar ou mordiscar (GIORDANO; APREA, 2003).

Dentre os animais, o cão doméstico (Canis lupus familiaris), é indubitavelmente, o animal mais atingido, especialmente quando este é um cão sem tutor ou que se encontra em um Centro de Vigilância Ambiental e Zoonoses (ARRUDA et al., 2018). Embora este acaro epidérmico priorize os cães da espécie Canis lupus familiaris, também pode afetar o gato Felis catus, a raposa-vermelha Vulpes vulpes e o próprio homem (TAYLOR; COOP; WALL, 2017).

O diagnóstico da presença destes ácaros no animal é feito, a princípio, pelo aspecto clínico do cachorro. Realiza-se, também, uma confirmação da presença do ácaro na pele por meio de um exame, que é a raspagem da pele e a observação deste material no microscópio. $\mathrm{O}$ relato de aparecimento simultâneo de outros casos de sarna na mesma região geográfica de onde vem o animal avaliado, ajuda a limitar as possibilidades de diagnóstico (GIORDANO; APREA, 2003).

Uma vez diagnosticado a doença, o tratamento deve consistir na medicação acaricida associada a fármacos sintomática, se necessário, (terapia do prurido, banhos antissépticos, suplementos nutricionais específicos). A medicação acaricida pode ser administrada sob a forma injetável (sempre pelo médico veterinário), banhos medicamentosos ou por via oral (FERRARI et al., 2008).

Segundo relatos de médicos veterinários na prática clínica, o tratamento injetável possui uma eficácia de $100 \%$, quando acompanhado por tratamento sintomático adequado. 
Depois de iniciado o tratamento, em poucos dias já é possível observar as melhorias no aspecto do animal e o total restabelecimento deste ocorre duas semanas após (FERRARI et al., 2008; GIORDANO; APREA, 2003; TAYLOR; COOP; WALL, 2017).

Animais com lesões parasíticas mais graves podem levar mais tempo para a recuperação total, devido às dificuldades apresentadas para reverter as alterações produzidas na pele do animal, como seborreia oleosa, hiperqueratose, hiperpigmentação. Estes animais devem ser rigorosamente isolados dos demais, e os veterinários que lidarem com estes animais devem usar os EPIs adequados ao realizar o tratamento, evitando ao máximo o risco de contágio desta doença pela pele. $\mathrm{O}$ ambiente contaminado deve ser higienizado e tratado com um produto acaricida dentro do tempo especificado do produto (CARMEN, 2006).

O ácaro adulto é microscópico, possui uma forma grosseiramente circular e se caracteriza por dois pares de pernas curtas craniais (que portam longas hastes não-articuladas com ventosas) e dois pares de pernas rudimentares caudais, que não se estendem além da borda do corpo (MONTEIRO, 2017).

O parasita completa o seu ciclo vital (ovo - larva - ninfa - adulto) em 17 a 21 dias nos túneis do estrato córneo do hospedeiro. A sarna sarcóptica é altamente contagiosa e é primariamente transmitida através do contato direto, mas os instrumentos de higiene e os canis podem albergar os ácaros. (BIRCHARD; SHERDING, 1998).

Tratar com escabicida os cães acometidos e todos aqueles que tiveram contato. $\mathrm{O}$ tratamento tradicional consiste em banhar os cães com um xampu anti-seborréico para remover crostas, seguido da aplicação de um escabicida tópico, por todo o corpo, em intervalos de 7 dias durante, no mínimo, 5 semanas. Os produtos tópicos eficazes incluem: Solução de sulfeto de cálcio $2 \%$ a $3 \%$, organoclorados, organofosforados e lactona macrocíclica (FERRARI et al., 2008; MEDLEAU; HNILICA, 2003).

Em virtude de reação de hipersensibilidade, pode levar até 4 a 6 semanas para que desapareçam o prurido intenso e os sinais clínicos. Tratamentos tópicos tendem a falhar, quando ocorre aplicação desuniforme da solução de tratamento e pode ressurgir se o contato com cães contaminados continuar (RHODES, 2005).

Considerar sempre sarna sarcóptica como uma possível causa de prurido em cães alérgicos que deixam de responder a terapia esteroide. Pessoas que entram em contato com um cão afetado podem desenvolver erupção cutânea popular pruriginosa nos braços, tórax ou abdômen. Lesões em seres humanos geralmente são transitórias, e estes poderão se restabelecer espontaneamente depois que o animal afetado tiver sido tratado; se as lesões persistirem, os clientes deverão consultar um dermatologista (RHODES, 2005). 


\section{CONCLUSÕES}

O cão doméstico (Canis lupus familiaris), é indubitavelmente, o animal mais atingido e o tratamento, adequadamente indicado por um médico veterinário, devem incluir, fármaco acaricida, associada a medicação sintomática, quando for necessário. O isolamento dos animais infectados deve ser incondicional, visando minimizar os riscos de contágio desta doença de pele. $\mathrm{O}$ ambiente contaminado por ácaros deve ser higienizado e tratado com um produto acaricida, e todos os animais que tenham contato com o animal contaminado, devem ser tratados simultaneamente.

\section{REFERÊNCIAS}

ARRUDA, K.B.; FURTADO, G.D.; VIEIRA, D.S. Ecología urbana y control poblacional de animales domésticos. Environmental Smoke, v. 1, n. 1, 2018.

BIRCHARD, S.J., SHERDING, R.G. Manual Saunders: clínica de pequenos animais. São Paulo: Roca, 1998.

CARMEN, L.M. Sarna sarcóptica, claves de su importancia en el protocolo diagnóstico de prurito en el perro. RECVET, v. 1, n. 1, p. 4, 2006.

FERRARI, M.L.O.P.; PRADO, M.O.; SPIGOLON, Z.; PICCININ, A. Sarna sarcóptica em cães. Revista Científica Eletrônica de Medicina Veterinária; ano VI, n. 10, 2008.

GIORDANO, A. L., APREA, A. N. Sarna sarcóptica (escabiosis) en caninos: actualidad de una antigua enfermedad. Analecta Veterinaria, v. 23, n. 1, p. 42-46, 2003.

MEDLEAU, L.; HNILICA, K.A. Dermatologia de pequenos animais: atlas colorido e guia terapêutico. São Paulo: Roca, 2003.

MONTEIRO, S.G. Parasitologia na medicina veterinária. Rio de Janeiro: Roca, 2017.

RHODES, K.H. Dermatologia de pequenos animais: consulta em 5 minutos. São Paulo: Revinter, 2005. 
TAYLOR, M.A.; COOP, R.L.; WALL, R.L. Parasitologia veterinária. 4.ed. Rio de Janeiro: Guanabara-Koogan, 2017. 